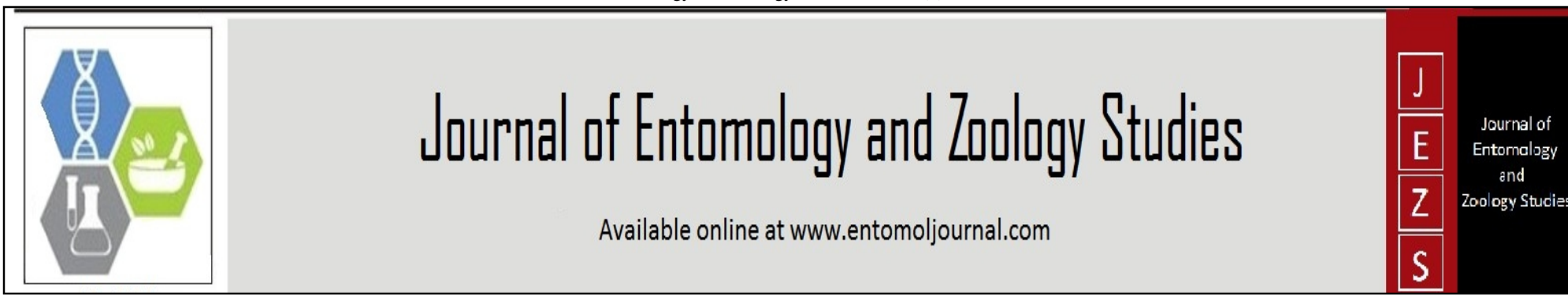

\section{ISSN $2320-7078$}

J EZS 2014; 2 (6): 01-08

(C) 2014 J EZS

Received: 01-10-2014

Accepted: 27-10-2014

\section{Dilbar Hussain}

Entomological Research I nstitute, AyubAgricultural Research Institute(AARI), F ai salabad, Pakistan.

\section{Hafiz Muhammad Saleem}

Entomological Research I nstitute, AyubAgriaultural Research Institute(AARI) , F ai salabad, Pakistan.

\section{Muhammad Saleem}

Entomological Research Institute, Ayub Agricultural Research Institute (AARI), F aisal abad, Pakistan.

\section{Muneer Abbas}

Entomological Research I nstitute, AyubAgricultural Research Institute(AARI ), F ai salabad, Pakistan.

\section{Correspondence}

\section{Muhammad Saleem}

Entomological R esearch

Institute, Ayub Agricultural

Research I nstitute (AARI),

Faisalabad, Pakistan.

\section{Monitoring of Insecticides Resistance in Field Populations of Helicoverpa armigera (Hub.) (Lepidoptera: Noctuidae)}

\author{
Dilbar Hussain, Hafiz Muhammad Saleem, Muhammad Saleem and \\ Muneer Abbas
}

\section{Abstract}

Helicoverpa armigera is a notorious pest of field crops and causes enormous financial loss, due to the excessive use of insecticides which contributes to multiple instances of insecticide resistance. The aim of this study was to investigate the toxicity of some new insecticides, which are being used on a large scale in Pakistan against $H$. armigera. Test insects were collected from three different locations of Punjab for three consecutive years. Resistance Ratios (RR), calculated as ratio of the $\mathrm{LC}_{50}$ for each field population relative Lab-PK, showed that the toxicity of profenofos compared with the Lab-Pk strain was in the range of the 9.80-12.11-fold, 1.69-5.22-fold for emamectin benzoate, 19.6-68.17-fold for lambdacyhalothrin, 3.48-9.62-fold for chlorpyrifos, 34.1-48.0-fold for bifenthrin, 19.33-37.17-fold for deltamethrin and 5.60-11.50-fold for thiodicarb. The Resistance. Ratio of the Insect Growth. Regulator (IGR) was in the range of 5.98-11.83-fold for the methoxyfenozide and 1.01-2.19-fold for lufenuron. Pair wise comparison of the $\log \mathrm{LC}_{50}$ of insecticides against all populations showed a correlation between the various insecticides, suggesting cross resistance was occurring. When these same insecticides were tested for susceptible population (Lab-Pk), emmamectin benzoate and lufenuron were significantly more toxic than other tested insecticides.

Keywords: Insecticide resistance, Helicoverpa armigera, pyrethroids, organophosphate

\section{Introduction}

Helicoverpa armigera (Hub.) (Lepidoptera: Noctuidae), also known as the cotton bollworm is classified as one of the top 100 world invasive species ${ }^{[21]}$. This is a cosmopolitan insect and has gained importance as a major destructive pest owing to its capacity to feed on many a variety of plant species, some of which are important agricultural crops ${ }^{[15]}$. Due to its wide host range, production of multiple generations per year, high fecundity, migratory behavior and pronounced resistance to many insecticides, the control up to desired level has become difficult ${ }^{[26]}$. Crops such as cotton, chickpea, tomato, sunflower, okra, pea, tobacco, potato, egg plant are particularly affected by $H$. armigera. Due to its tremendous damage to crops, the use of insecticides constitutes the main control strategy in Pakistan ${ }^{[9]}$. However, the indiscriminate use of insecticides has resulted in the development of resistance in many $H$. armigera populations ${ }^{[16,32]}$. Resistance to a wide range of insecticides in $H$. armigera has been reported world-wide, including Pakistan [26]. Moderate to high level of resistance to conventional insecticides such as (chlorinated hydrocarbons, organophosphates, carbamates and pyrethroids) as well as to neonicotinoids pesticides and Insect Growth Regulator (IGR) has been reported in field populations of $H$. armigera $^{[6,28]}$. Further, H. armigera showed moderate to high resistance, especially in Punjab, Pakistan against conventional insecticides and neonicotinoids ${ }^{[2]}$.

Pesticide resistance to insects arises due to intense selection pressure produced by overuse or misuse of pesticides, because insecticides act quickly and have a very high kill rate prior to the advent of resistance, growers are reluctant to use alternative methods of controlling insects which do not share these properties ${ }^{[14]}$. Selection for resistance to insecticides in the laboratory and the field is an example of natural selection, and the components which are responsible for the increase in resistance are associated the mutations which are applied importance ${ }^{[9]}$.

Monitoring the development of insecticide resistance is crucial to devising a successful Insecticide Resistance Management (IRM) scheme ${ }^{[18]}$. IRM not only helps to document the 
geographical and variability in populations to insecticides, but also gives an early warning of coming resistance problems and identifies which pesticides are no longer effective due to resistance ${ }^{[10]}$. Due to the development of resistance to conventional insecticides in Pakistan, insecticides with new chemical mechanisms were employed in late 1990s for the control of chewing and sucking insect pests of cotton ${ }^{[3]}$. After the reports of failure of these insecticides and lack of documented resistance reports in Pakistan, the current study was undertaken to measure the change in the susceptibility to new molecule insecticides, stability of resistance in the field, and efficacy of neonicotinoids to larvae.

We further examined the changes in baseline toxicity through detection of variability in toxicity of different insecticides to $H$. armigera in three agro-ecological regions (Multan, Bahawalpur and Faisalabad) of the Punjab, Pakistan which can be very useful for the development of appropriate IRM strategies.

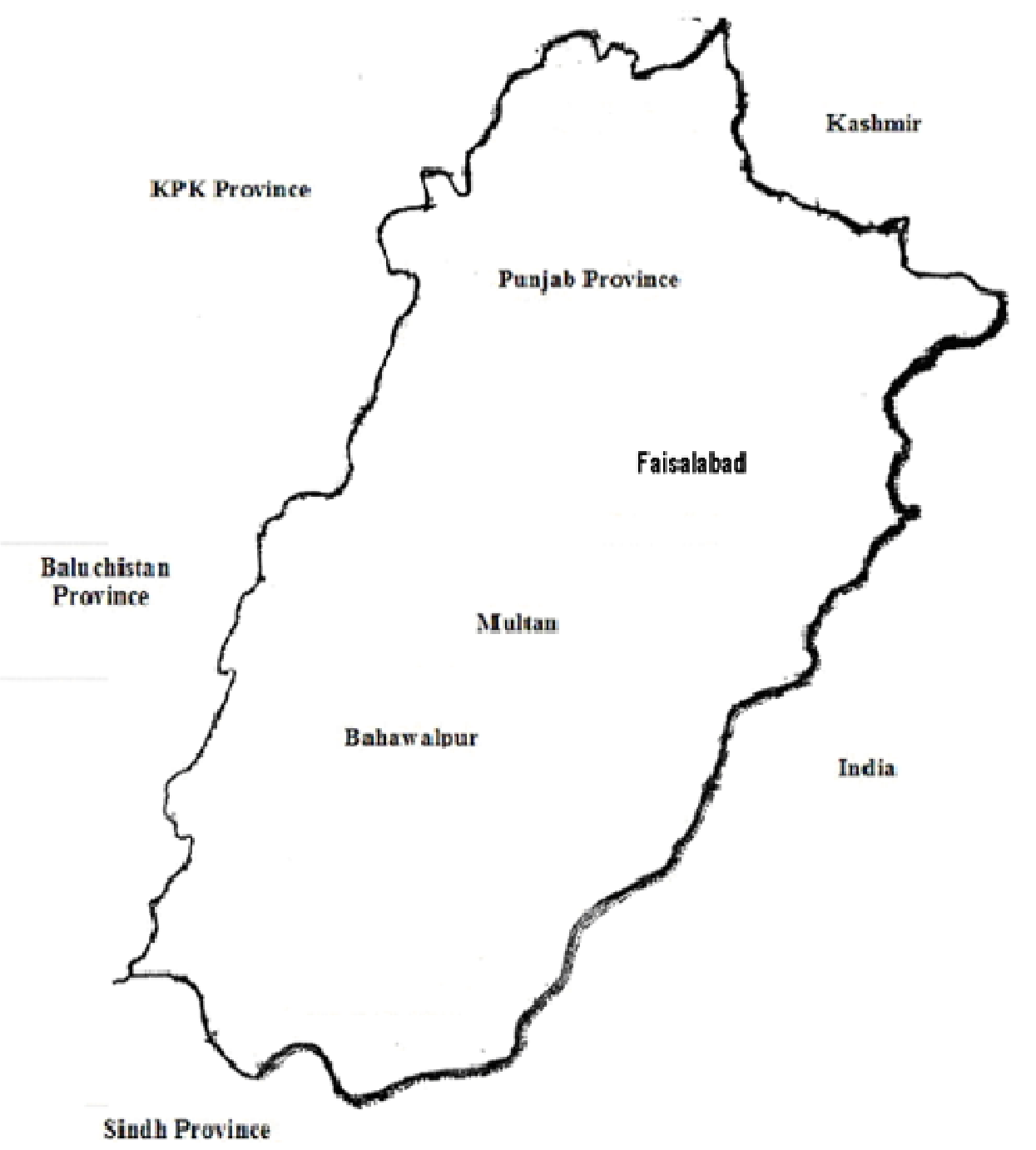

Fig 1: Location where $H$. armigera were collected from Pakistan

\section{Materials and Methods \\ 2.1 Test Insects Culture.}

The $5^{\text {th }}$ and $6^{\text {th }}$ instars of $H$. armigera were collected from cotton fields of three districts, which are approximately 100 kms apart: Faisalabad, Multan and Bahawalpur, Punjab Pakistan (Fig.1). The collection areas were under the jurisdiction of the Director Entomological Research Institute Faisalabad. Each collection of 1000 larvae was made by walking through a plot of 2.20 hectares of selected host crop from each location and larvae were placed in the insecticide resistance laboratory at the Entomological Research Institute, Ayub Agricultural Research Institute Faisalabad during cropping season 2009 to 2011. A susceptible strain of $H$. armigera was selected for susceptibility in the laboratory as described in ${ }^{[3]}$ and labeled as Lab-Pak. The strain has been maintained in the laboratory for 5 years without exposure to

\section{pesticides}

Larvae were reared in the laboratory on semi-synthetic wheat germ based diet at $25 \pm 2{ }^{\circ} \mathrm{C}$ and $65 \pm 5 \%$ relative humidity with a 14:10 h light: dark photoperiod ${ }^{[32]}$ Diet was reinstated after $24 \mathrm{~h}$, and pupae were collected on sequential days. The adults that emerged from larvae were kept in Perspex oviposition cages $(30 \times 30 \times 30 \mathrm{~cm})$ with two sides covered with muslin cloth to maintain ventilation and fed on a solution containing sucrose $(100 \mathrm{~g})$, vitamin solution $(20 \mathrm{ml})$ and methyl 4hydroxybenzoate was presented on a soaked cotton wool ball [3].

\subsection{Insecticides}

Monitoring of insecticide resistance bioassays was conducted by using different commercial formulations of insecticides included profenofos (Curacron 500 EC, Sygenta crop 
protection Switzerland) emmamectin benzoate ( Proclaim 1.9 EC, Sygenta crop protection Switzerland) lambda-cyhalothrin (Karate 2.5 EC, Sygenta crop protection Switzerland) chlorpyrifos (Lorsban 40 EC, Dow AgroSciences, UK) Bifenthrin (Talstar 10 EC, FMC Philadelphia, PA) lufenuron (Match 50 EC, Sygenta crop protection Switzerland) deltamethrin (Decis 2.5 EC, Bayer Crop Science, Leverkusen, Germany) thiodicarb (Larvin 80 DF, Bayer Crop Science, Leverkusen, Germany)

\subsection{Bioassays Studies}

Bioassays was conducted on newly molted $2^{\text {nd }} / 3^{\text {rd }}$ instars larvae (30-40 mg) by using a leaf dip bioassay technique recommended as the Insecticide Resistance Action Committee ${ }^{[7]}$ on $F_{2}$ laboratory cultures exposed to different insecticides. Because the Resistance Ratio is best expressed in the $2^{\text {nd }}$ and $3^{\text {rd }}$ instars of $H$. Armigera ${ }^{[13]}$, this stage was selected for resistance monitoring. Technical grade insecticides were diluted by serial dilution using distilled water as a solvent. Leaf discs of $5 \mathrm{~cm}$ diameter were taken from unsprayed fresh leaves, dipped into the test solution for $10 \mathrm{~s},{ }^{[35]}$ dried on paper. towel, and then they were transferred to moist filter paper in plastic Petri dishes (5-cm diameter). Five newly moulted larvae were placed on each dried leaf disc and then the dish was covered with a plastic lid. Eight replicates each of seven concentrations and one control (untreated) were used for each test insecticide. The test containers containing larvae were covered with black paper to reduce the risk of cannibalism and kept at constant. Temperature $\left(25 \pm 2{ }^{\circ} \mathrm{C}\right.$ for 48 hours). Mortality was recorded after a 48 hours exposure period. Larvae were regarded as dead when they were not able to move when probed with a blunt probe or brush.

\subsection{Data Analysis}

Mortality data were corrected by using Abbott's formula [1] where necessary and analyzed by probit analysis ${ }^{[17]}$ using the
POLO-PC ${ }^{[24]}$. The estimation of $\mathrm{LC}_{50}$ values and their $95 \%$ fiducial limits (FL) were acquired by probit analysis using POLO. Due to the inherent .variability of bioassays, pair-wise comparison to $\mathrm{LC}_{50}$ values was made at the $1 \%$ significance level, where individual 95\% FL for two treatments did not overlap ${ }^{[25]}$. Resistance Ratios were ascertained by dividing the $\mathrm{LC}_{50}$ values of each field population by the $\mathrm{LC}_{50}$ of Lab-PK. The level of insecticide .resistance was determined using the methods described by Ahmad et al ${ }^{[5]}$ and Torres-Vila et al ${ }^{[38]}$. According to these sources, levels of resistance were defined as follows- susceptible ( $R R=0-1)$, tolerance to low level of resistance $(R R=2-10)$, moderate resistance $(R R=11-30)$, high resistance $(R R=31-100)$ and very high resistance $(R R>100)$.

\section{Results}

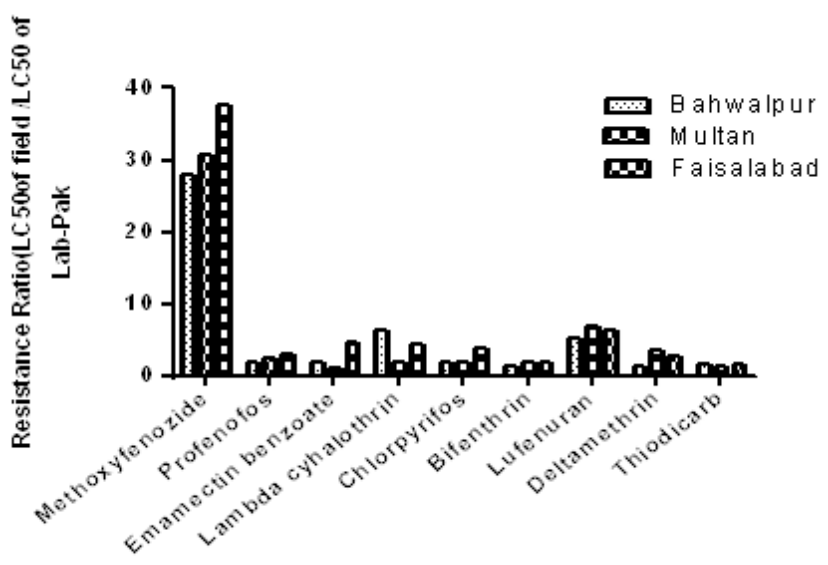

In secticides

Fig 2: Effect of insecticide on development of resistance in Helicoverpa armigera collected in different areas of Pakistan

Table 1: Response to the field collected populations of $H$. armigera to various insecticides

\begin{tabular}{|c|c|c|c|c|c|c|c|c|c|c|c|}
\hline \multirow{2}{*}{ Insecticides } & \multirow{2}{*}{ location } & \multirow{2}{*}{$\begin{array}{c}\text { Year } \\
\text { Tested }\end{array}$} & \multirow{2}{*}{$\mathbf{n}^{\mathrm{n}}$} & \multirow{2}{*}{$\begin{array}{c}\mathrm{LC}_{50} \\
\mu \mathrm{g} / \mathrm{ml}\end{array}$} & \multirow{2}{*}{$95 \% \mathrm{FL}$} & \multicolumn{4}{|c|}{ Fit of probit analysis } & \multirow{2}{*}{$\mathbf{R R}^{\mathbf{b}}$} & \multirow{2}{*}{$\mathbf{D R}^{\mathrm{c}}$} \\
\hline & & & & & & Slope \pm S.E & $x^{2}$ & $\mathrm{P}$ & $\mathrm{df}$ & & \\
\hline \multirow{4}{*}{ Methoxyfenozide } & Lab-Pk & - & 280 & 1.05 & $(0.86-1.13)$ & $2.34 \pm 0.22$ & 0.22 & 0.96 & 6 & 1 & ----- \\
\hline & Bahawalpur & $\begin{array}{l}2009 \\
2010 \\
2011\end{array}$ & 280 & 29.29 & $(23.1-36.4)$ & $2.24 \pm 0.22$ & 7 & 0.30 & 6 & 29.15 & \multirow{3}{*}{-0.22} \\
\hline & Multan & $\begin{array}{l}2009 \\
2010 \\
2011\end{array}$ & 280 & 32.18 & $(26.3-39.40)$ & $1.46 \pm 0.29$ & 3.48 & 0.32 & 6 & 64.36 & \\
\hline & Faisalabad & $\begin{array}{l}2009 \\
2010 \\
2011\end{array}$ & 280 & 39.41 & (34.11-47.77) & $1.71 \pm 0.17$ & 3.76 & 0.41 & 6 & 14.50 & \\
\hline \multirow{4}{*}{ Profenofos } & Lab-Pk & - & 280 & 11.23 & $(8.67-13.21)$ & $2.13 \pm 0.67$ & 0.58 & 0.71 & 5 & 1 & $\begin{array}{ll}----- \\
\end{array}$ \\
\hline & Bahawalpur & $\begin{array}{l}2009 \\
2010 \\
2011\end{array}$ & 280 & 21.16 & $(17.22-27.90)$ & $1.06 \pm 0.19$ & 2.32 & 0.65 & 5 & 10.23 & \multirow{3}{*}{-0.26} \\
\hline & Multan & $\begin{array}{l}2009 \\
2010 \\
2011\end{array}$ & 280 & 27.93 & $(21.22-35.32)$ & $1.04 \pm 0.23$ & 2.15 & 0.92 & 5 & 12.11 & \\
\hline & Faisalabad & $\begin{array}{l}2009 \\
2010 \\
2011\end{array}$ & 280 & 34.89 & $(28.75-41.21)$ & $1.56 \pm 0.91$ & 3.11 & 0.95 & 5 & 9.80 & \\
\hline \multirow{3}{*}{$\begin{array}{l}\text { Emmamectin } \\
\text { benzoate }\end{array}$} & Lab-Pk & - & 280 & 0.11 & $(0.08-0.18)$ & $1.89 \pm 0.52$ & 0.13 & 0.78 & 6 & 1 & ------ \\
\hline & Bahawalpur & $\begin{array}{l}2009 \\
2010 \\
2011\end{array}$ & 280 & 0.22 & $(0.11-0.28)$ & $1.42 \pm 0.13$ & 8.05 & 0.11 & 6 & 1.69 & \multirow{2}{*}{-0.21} \\
\hline & Multan & $\begin{array}{l}2009 \\
2010\end{array}$ & 280 & 0.13 & $(0.12-0.19)$ & $1.80 \pm 0.22$ & 6.17 & 0.83 & 6 & 5.22 & \\
\hline
\end{tabular}




\begin{tabular}{|c|c|c|c|c|c|c|c|c|c|c|c|}
\hline & & 2011 & & & & & & & & & \\
\hline & Faisalabad & $\begin{array}{l}2009 \\
2010 \\
2011\end{array}$ & 280 & 0.52 & $(0.44-0.61)$ & $2.74 \pm 0.17$ & 5.79 & 0.92 & 6 & 4.00 & \\
\hline \multirow{4}{*}{$\begin{array}{l}\text { Lambda- } \\
\text { cyhalothrin }\end{array}$} & Lab-Pk & - & 280 & 8.43 & $(4.16-13.75)$ & $1.98 \pm 0.21$ & 1.2 & 0.99 & 6 & 1 & ------ \\
\hline & Bahawalpur & $\begin{array}{l}2009 \\
2010 \\
2011\end{array}$ & 280 & 55.02 & $(51.23-61.89)$ & $1.63 \pm 0.23$ & 2.71 & 0.67 & 6 & 68.17 & \multirow{3}{*}{-0.17} \\
\hline & Multan & $\begin{array}{l}2009 \\
2010 \\
2011 \\
\end{array}$ & 280 & 15.68 & $(12.56-18.76)$ & $1.72 \pm 0.16$ & 3.18 & 0.56 & 6 & 19.6 & \\
\hline & Faisalabad & $\begin{array}{l}2009 \\
2010 \\
2011 \\
\end{array}$ & 280 & 37.54 & $(33.54-42.11)$ & $1.53 \pm 0.15$ & 5.87 & 0.57 & 6 & 48.52 & \\
\hline \multirow{4}{*}{ Chlorpyrifos } & Lab-Pk & - & 280 & 2.45 & $(0.56-4.19)$ & $2.11 \pm 0.11$ & 2.10 & 0.45 & 6 & 1 & ------ \\
\hline & Bahawalpur & $\begin{array}{l}2009 \\
2010 \\
2011\end{array}$ & 280 & 4.56 & $(3.11-6.11)$ & $1.63 \pm 0.18$ & 4.02 & 0.94 & 6 & 3.48 & \multirow{3}{*}{-0.19} \\
\hline & Multan & $\begin{array}{l}2009 \\
2010 \\
2011\end{array}$ & 280 & 4.75 & $(3.02-5.39)$ & $1.70 \pm 0.17$ & 4.49 & 0.84 & 6 & 9.62 & \\
\hline & Faisalabad & $\begin{array}{l}2009 \\
2010 \\
2011 \\
\end{array}$ & 280 & 9.63 & $(7.90-13.28)$ & $1.35 \pm 0.16$ & 6.17 & 0.78 & 6 & 5.65 & \\
\hline \multirow{4}{*}{ Bifenthrin } & Lab-Pk & - & 280 & 16.12 & $(11.56-21.63)$ & $1.98 \pm 0.11$ & 1.22 & 0.96 & 6 & 1 & ---- \\
\hline & Bahawalpur & $\begin{array}{l}2009 \\
2010 \\
2011 \\
\end{array}$ & 280 & 22.86 & $(18.79-25.23)$ & $1.81 \pm 0.18$ & 5.78 & 0.49 & 6 & 34.1 & \multirow{3}{*}{-0.23} \\
\hline & Multan & $\begin{array}{l}2009 \\
2010 \\
2011\end{array}$ & 280 & 31.40 & $(28.12-36.87)$ & $1.28 \pm 0.16$ & 5.23 & 0.31 & 6 & 48.0 & \\
\hline & Faisalabad & $\begin{array}{l}2009 \\
2010 \\
2011\end{array}$ & 280 & 32.18 & $(28.93-37.23)$ & $1.56 \pm 0.16$ & 6.01 & 0.98 & 6 & 40.08 & \\
\hline \multirow{4}{*}{ Lufenuron } & Lab-Pk & - & 280 & 0.10 & $(0.05-1.23)$ & $1.25 \pm 0.41$ & 1.32 & 0.54 & 5 & 1 & ----- \\
\hline & Bahawalpur & $\begin{array}{l}2009 \\
2010 \\
2011 \\
\end{array}$ & 280 & 0.53 & $(0.43-0.61)$ & $1.47 \pm 0.12$ & 2.67 & 0.94 & 5 & 1.70 & \\
\hline & Multan & $\begin{array}{l}2009 \\
2010 \\
2011\end{array}$ & 280 & 0.68 & $(0.62-0.71)$ & $1.35 \pm 0.18$ & 2.93 & 0.89 & 5 & 2.19 & \multirow[b]{2}{*}{-0.18} \\
\hline & Faisalabad & $\begin{array}{l}2009 \\
2010 \\
2011 \\
\end{array}$ & 280 & 0.63 & $(0.55-0.67)$ & $1.55 \pm 0.19$ & 3.19 & 0.66 & 5 & 1.01 & \\
\hline \multirow{4}{*}{ Deltamethrin } & Lab-Pk & - & 280 & 67.23 & $(59.45-78.49)$ & $2.23 \pm 0.71$ & 1.89 & 0.91 & 6 & 1 & ----- \\
\hline & Bahawalpur & $\begin{array}{l}2009 \\
2010 \\
2011\end{array}$ & 280 & 96.46 & $\begin{array}{l}(87.56- \\
104.90)\end{array}$ & $1.92 \pm 0.18$ & 1.77 & 0.44 & 6 & 28.21 & \multirow{3}{*}{-0.16} \\
\hline & Multan & $\begin{array}{l}2009 \\
2010 \\
2011 \\
\end{array}$ & 280 & 241.04 & $\begin{array}{l}(222.53- \\
257.11)\end{array}$ & $1.84 \pm 0.16$ & 5.03 & 0.71 & 6 & 37.17 & \\
\hline & Faisalabad & $\begin{array}{l}2009 \\
2010 \\
2011 \\
\end{array}$ & 280 & 195.34 & $\begin{array}{c}(186.30- \\
211.34)\end{array}$ & $1.97 \pm 0.13$ & 4.11 & 0.40 & 6 & 19.33 & \\
\hline \multirow{4}{*}{ Thiodicarb } & Lab-Pk & - & 280 & 41.23 & $(36.98-51.32)$ & $2.11 \pm 0.26$ & 2.76 & 0.36 & 6 & 1 & ----- \\
\hline & Bahawalpur & $\begin{array}{l}2009 \\
2010 \\
2011 \\
\end{array}$ & 280 & 70.91 & (63.11-74.89) & $1.50 \pm 0.14$ & 5.43 & 0.74 & 6 & 7.21 & \multirow{3}{*}{-0.27} \\
\hline & Multan & $\begin{array}{l}2009 \\
2010 \\
2011\end{array}$ & 280 & 52.45 & $(47.23-56.74)$ & $1.71 \pm 0.16$ & 4.91 & 0.76 & 6 & 11.50 & \\
\hline & Faisalabad & $\begin{array}{l}2009 \\
2010 \\
2011\end{array}$ & 280 & 65.71 & $(59.30-71.25)$ & $2.09 \pm 0.22$ & 5.85 & 0.63 & 6 & 5.60 & \\
\hline
\end{tabular}

$\mathrm{n}^{\mathrm{a}}$, number of insects used in bioassay, including control.

${ }^{\mathbf{b}} \mathrm{RR}$, Resistance Ration, calculated as $\left(\mathrm{LC}_{50}\right.$ of field pop / $\mathrm{LC}_{50}$ of Lab-Pk

${ }^{\mathrm{c}} \mathrm{DR}$, rate of decrease in $\mathrm{LC}_{50}\left(\log _{10}\right.$ (final $\mathrm{LC}_{50}-$ initial $\left.\mathrm{LC}_{50}\right) / \mathrm{n}$, where $\mathrm{n}$ is no. of generation) 
Table 2: Pairwise correlation coefficient comparison between $\log \mathrm{LC}_{50}$ of insecticides

\begin{tabular}{|c|c|c|c|c|c|}
\hline Insecticides & Bifenthrin & Thiodicarb & Profenofos & Emamectin & Methoxyfenozide \\
\hline Thiodicarb & $-0.07^{\text {ns }}$ & & & & \\
\hline Profenofos & $0.09^{\text {ns }}$ & $-0.66^{0.05}$ & & & \\
\hline Emamectin & $0.14^{\text {ns }}$ & $0.43^{\text {ns }}$ & $-0.05^{\text {ns }}$ & & \\
\hline Methoxyfenozide & $0.48^{\text {ns }}$ & $-0.33^{\text {ns }}$ & $0.61^{0.05}$ & $-0.44^{\text {ns }}$ & \\
\hline Lufenuron & $0.05^{\text {ns }}$ & $0.47^{\text {ns }}$ & $0.03^{\text {ns }}$ & $0.93^{0.01}$ & $-0.22^{\text {ns }}$ \\
\hline
\end{tabular}

\subsection{Toxicity of test insecticides against the laboratory susceptible populations}

Bioassay results from a reference population ( $\mathrm{Lab}-\mathrm{Pk}$ ) showed that emmamectin benzoate proved significantly $(\mathrm{P}<0.01)$ more toxic than all other insecticides viz., bifenthrin, thiodicarb, lambda-cyhelothrin, profenofos, deltamethrin and chlorpyrifos. Deltamethrin was least potent compared to other tested insecticides (Table 1). The slopes of the regression line of bifenthrin, thiodicarb, lambda cyhelothrin, profenofos, deltamethrin and chlorpyrifos .were similar (overlapping of $95 \% \mathrm{FL}, \mathrm{P}>0.05)$. Among the insect growth regulator (IGR), Lufenuron was notably more toxic $(\mathrm{P}<0.01)$ than methoxyfenozide (Table 1).

\subsection{Toxicity of insecticides to the field population}

Toxicity of profenofos was significantly lower (nonoverlapping of $95 \% \mathrm{FL}, \mathrm{P}<0.05)$ for field populations compared with the Lab-Pk (Table 1). The resistance to profenofos from all three district samples was found to show moderate resistance, with the Resistance Ratio commonly more than 10- fold as compared with Lab-Pk population. The maximum level of resistance (12.11-fold) compared with Lab$\mathrm{Pk}$ was observed in Multan district, where-as a minimum level of resistance (9.80-fold) compared with Lab-Pk was observed in Faisalabad. Because profenofos was especially targeted against $H$. armigera and $E$. vittella, it might have developed a moderate level of resistance to $H$. armigera from Pakistan. The population exposed to emmamectin benzoate had a low level of resistance compared with Lab-Pk. The maximum resistance ratio was 5.22-fold in the Multan district while, minimum resistance ratio was 1.69-fold in Faisalabad district. The slope for regression line was similar for all three districts.

Lambda-cyhalothrin showed a high level of resistance (19.6 68.17-fold) in field strains of $H$. armigera compared with Lab$\mathrm{Pk}$. However, the highest ratio was found in H. armigera from Bahawalpur district, while those from the Faisalabad district had a minimum resistance ratio (Table 1). The response of $H$. armigera from three different locations to chlorpyrifos and thiodicarb was similar. Low levels of tolerance, with resistance ratios of 3.48-, 9.62-, 5.65-, 7.21- and 5.60-fold were seen in the field strain when compared to Lab-Pk. However, moderate resistance level was seen in response to thiodicarb (11.50-fold) in field populations from Multan districts (Table 1).

The Resistance Ratio of bifenthrin and deltamethrin were 34.1fold, 48.0-, 40.08-, 28.21-, 37.17- and 19.33-fold respectively (Table 1) in field populations (from all three locations) compared with Lab-Pk. Both insecticides showed high level of resistance to all three mentioned districts. The slopes of the regression lines of the insecticides tested for field populations were significantly lofty for emmamectin benzoate, lambdacyhalothrin, bifenthrin, thiodicarb, chlorpyrifos and deltamethrin compared with Lab-Pk, suggesting a homogenous response to the field collected populations to above mentioned insecticides. The slope of the line for profenofos, however, was smaller than the other insecticides, but it was similar to Lab-Pk (Table 1). The response of $H$. armigera toward the tested insecticides collected from three different locations was similar, however, the highest Resistance Ratio was produced against the field population collected from the Multan district (Fig. 2)

\subsection{Toxicity of insect growth regulators (IGR) to field population}

Two insect growth regulators were also used in the present studies to determine whether $H$. armigera has evolved resistance to IGR but with the use of Methoxyfenozide for bioassays on three different districts field-collected populations. However the studies revealed that Multan population of $H$. armigera district has evolved significantly higher levels of resistance $(\mathrm{P}<0.01)$ to methoxyfenozide than $H$. armigera from the Faisalabad district which showed a low level of resistance (Table 1). H. armigera population of Bahawalpur district showed a moderate level of resistance.

Lufenuron, a chitin synthesis inhibitor which is currently not being widely used, proved effective in killing $H$. armigera collected from all three districts. The Resistance Ratios for lufenuron were 2.19-fold, 1.70- and 1.01-fold for H. armigera tested from Multan, Bahawalpur and Faisalabad respectively (Table 1).

\subsection{Pair-wise correlations .between Log Lcso of different insecticides}

The toxicity of methoxyfenozide and lufenuron from the IGR group were negatively correlated with other insecticides tested. The methoxyfenozide was positively correlated with bifenthrin, profenofos and negatively correlated with thiodicarb and emmamectin benzoate (Table 2). The resistance to bifenthrin was negatively correlated with resistance to thiodicarb; however, a positive but non-significant correlation was observed between bifenthrin, profenofos and emmamectin benzoate. The $\mathrm{LC}_{50}$ value of thiodicarb was negatively correlated with profenofos and methoxyfenozide but positively correlated with lufenuron and emamectin benzoate (Table 2).

\subsection{Retrogression of Resistance to insecticides in the field} In order to study the stability of resistance to the insecticides, the field population was sustained for six generations of exposure to insecticides. When challenged with methoxyfenozid after six generations without exposure to pesticides, the field population showed a significant reduction in its Resistance Ratio with a reversion rate of -0.22 . Similarly, rearing of field populations of exposure to other insecticides also reduces the Resistance Ratio of profenofos, emmamectin benzoate, lambda-cyhalothrin, chlorpyrifos, bifenthrin, lufenuron, deltamethrin and thiodicarb (Table 1). The retrogression rate of resistance to deltamethrin in the field population was the least $(-0.16)$ whereas it was the highest for the thiodicarb $(-0.27$, Table 1$)$. 


\section{Discussion}

The current investigation was conducted to provide insight into resistance phenomena of insecticides having novel modes of action against the important agricultural pest, $H$. armigera collected from three different districts of Punjab, Pakistan with different cropping patterns. The studies were undertaken during three consecutive years (2009-2011) Bioassay results showed varying degrees of resistance in field-caught populations of $H$. armigera collected from three different districts. High levels of resistance to the insecticides methoxyfenozide, lambda-cyhalothrin, bifenthrin and deltamethrin were detected. It has-been proposed that insects should not be regarded as resistant until a Resistance. Ratio of $10 \mathrm{X}$ is manifested ${ }^{[39]}$. Accordingly, we would consider the less than 10-fold reduction in sensitivity to emmamectin benzoate and profenofos to defined resistance level scales whereas the reaction of $H$. armigera to lufenuron, chlorpyrifos and thiodicarb could best be described as tolerance or a low level of resistance. In the Indo- Pakistan subcontinent $H$. armigera has already acquired significant resistance to

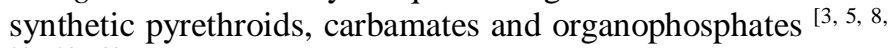
$22,23,30]$. The current studies indicate that this pest-might acquire resistance to new insecticides due to cross resistance mechanisms evolved against conventional insecticides such as pyrethroids and organophosphates ${ }^{[4]}$. There is significantly higher correlations found of resistance between profenofos and methoxyfenozide or lufenuron and emmamectin benzoate also suggest the presence of resistance mechanism to the insecticides having different modes of action. Various insecticides used in current study have multiple modes of action. For example profenofos and chlorpyrifos are acetylcholine esterase inhibitors, whereas emmamection benzoate binds the GABA-gated chloride channel and profenofos blocks it, however the level of resistance of $H$. armigera to insecticides in both groups was similar Shen and $\mathrm{Wu}{ }^{[36]}$ reported that it is practical to focus more on the insecticides application history. In the field as an explanatory mechanism when cross-.resistance detected. Mixing of new insecticides with conventional insecticides would also be a plausivle explanation for the development of multiple resistance problems which routinely occurred with $H$. armigera in the other parts of the world ${ }^{[40]}$. In our country, it is a common practice to mix newer insecticides with conventional insecticides to control insect pest of cotton: therefore, it would be logical to assume that a cross resistance between these compounds would occur. Currently we report that selection of $H$. armigera population of thiodicarb also increased the resistance to lambda-cyhelothrin, bifenthrin and emmamectin benzoate. We further found that monooxygenases were involved in cross-resistance between thiodicarb and lambda-cyhalothrin, bifenthrin or emmamectin benzoate ${ }^{[33,34]}$. The monooxygenases constitute many isoenzymes ${ }^{[20]}$ and if insecticides can selects with specific isoenzyme, which has activity on multiple insecticides, cross resistance could occur. Currently we are selecting $H$. armigera populations with emmamectin benzoate to analyze the potential for a cross resistance mechanism to newer insecticides with distinctly different mode of action, which are currently being used in our country.

Recently the control failure of the conventional insecticides and subsequent outbreak of $H$. armigera in Pakistan could be attributed to development of resistance to insecticides. The high $\mathrm{LC}_{50}$ values along with the high value of the slopes (Table 1 and 2) suggest that most of the individuals in the field population are resistant. Moreover, a inter-population variation in the slope was clear for a number of insecticides; For example this was the situation for profenofos (1.04) for Multan population and for thiodicarb (1.50) for Bahawalpur population. These data indicate that the population is still in the process of becoming resistant to insecticides because the regression slope showed the homogeneity of the population. i. e. pertinent mixture of resistance and susceptible population [29]. The data also suggest that the higher inter-population variation in the slope indicates that there are qualitatively different resistance mechanisms developing among the strains. Tabashnik et al. ${ }^{[37]}$ argued that variation in slopes was not biologically meaningful, and that the slope did not change in a simple and predictable predictor of $\mathrm{LC}_{50}$. Likewise Chilcutt and Tabashnik, ${ }^{[12]}$ proposed that slope was not a good indicator of the genetic variability in susceptible organisms and, further, that genetic variation was not related to the $\mathrm{LC}_{50}$. In the case of various insecticides high levels of resistance might reflect multiple resistance mechanism. ${ }^{[4]}$ No cross resistance was observed between profenofos and thiodicarb or bifenthrin and thiodicarb in other lepidopteron pest such as $S$. litura ${ }^{[31]}$. The entire insecticide compound has different sites of action on the insect nervous system [27]. Moreover, the finding of significantly $(\mathrm{P}<0.01)$ low level of resistance to lufenuron chlorpyrifos and emmamectin benzoate at three districts viz., Multan, Bahwalpur and Faisalabad is fascinating. It showed that an independent mechanism of resistance may be operative while low level of resistance showed less usage of the insecticides at these districts.

The significant retrogression in resistance.in three different districts suggested that in areas where resistance to specific insecticide was lower, the farmers enhanced the insecticide application. Due to increased application of insecticides, level of resistance in that cropping area increased. However, the mean resistance ratio of Multan district was significantly higher than the mean resistance ratio of Bahawalpur and Faisalabad. Rapid retrogression of resistance to the tested insecticides in the field collected populations suggests that high fitness costs may co-occur with resistance. The decline in resistance, further, may also be due to the presence of heterozygotes in the population. High levels of resistance to the conventional insecticides have been reported to the decline rapidly in fields or laboratory populations ${ }^{[11]}$.

In the present study we revealed a broad spectrum of resistance- levels which suggests the presence of more than one resistance mechanism. Monooxygenases and esterases are involved in producing resistance to thiodicarb and pyrethroids against $H$. armigera in Pakistan ${ }^{[33,34]}$. Our results are also endorsed by Armes et al, ${ }^{[8]}$ who suggested that monooxygenases-based resistance is typically found in response to pyrethroids while esterase-based resistance mechanisms are produced in response to organophosphates. The resistance mechanism to pyrethroids in $H$. armigera collected from China was reported to be increased metabolic detoxification of the monooxygenases while the organophosphates resistance mechanism was correlated with the increased in the monooxygenases and esterase activities ${ }^{[19}$, 41]

In Pakistan, $H$. armigera is the most critical pest of multiple field crops and the vegetables ${ }^{[5]}$. Hence, it is widely exposed to insecticide used on many infested crops. Exposure to this pest to diverse groups of insecticides throughout the year may also be involved in rapid evolution of resistance to new insecticides. This might be a main barricade to formulating an 
integrated pest management (IPM) programme. Moreover, the monitoring, using pheromones or light traps may be helpful in formulating the $H$. armigera management practices. Bacillus thuringiensis toxin (Crylca and Cry1F) which is also potent against $H$. armigera and other major insect pest such as, $S$. litura stacking them in the crop and using as IPM tool might be another auspicious .management strategy.

\section{Acknowledgment}

We thank to Susan W. Fisher Professor Emerita Department of Entomology, Ohio State University, Columbus for reading and commenting on earlier version of the manuscript

\section{References}

1. Abbott WS. A method of computing the effectiveness of an insecticide. J Econ Entomol 1925; 18:265-267.

2. Aheer GM, Zia MA, Hameed A, Ali A. Evaluation of resistance to different insecticides in field strains of Helicoverpa armigera (Lepidoptera: Noctuidae) in Punjab, Pakistan. Korian Entomol Res 2008; 39:159-167.

3. Ahmad M, Sayyed AH, Crickmore N, Saleem SA. Genetics and mechanism of resistance to deltamethrin in a field population of Spodoptera litura (Lepidoptera: Noctuidae). Pest Manag Sci 2007b; 63:1002-1010.

4. Ahmad M, Sayyed AH, Ahmad M, Ahmad M. Evidence for field evolved resistance to newer insecticides in Spodoptera litura (Lepidoptera: Noctuidae) from Pakistan. Crop Prot 2008; 27:1367-1372.

5. Ahmad M, Arif I, Ahmad M. Occurrence of insecticide resistance in field populations of Spodoptera litura (Lepidoptera: Noctuidae) in Pakistan. Crop Prot 2007a; 26:807-809.

6. Ahmad M, Arif MI, Ahmad Z. Monitoring insecticide resistance Helicoverpa armigera (Lepidoptera: Noctuidae) in Pakistan. J Econ Entomol 1995; 88:771-776.

7. Anonymous. Proposed insecticide/acaricide susceptibility tests, International Resistance Action Committee Method No.7. Bull Eur Plant Protect Org 1990; 20:399-400.

8. Armes NJ, Wightman JA, Jadhav DR, Ranga RGV. Status of insecticide resistance in Spodoptera litura in Andhra Pradesh India. Pestic Sci 1997; 50:240-248.

9. Basit M, Saeed S, Saleem MA, Denholm I, Shah M. Detection of resistance, cross resistance and stability of resistance to new chemistry insecticides in Helicoverpa armigera. J Econ Entomol 2013; 106:1414-1422.

10. Brent KJ. Detection and monitoring of resistant forms: an overview, In National Academy of Sciences, Pesticides Resistance: Strategies and Tactics for Management. National Academy Press, Washington, DC, 1986, 298312.

11. Carriere Y, Dennehy TJ, Pedersen B, Haller S, Ellers-Kirk C. Large scale management of insect resistance to transgenic cotton in Arizona: Can transgenic insecticidal crops be sustained? J Econ Entomol 2001; 94:315-325.

12. Chilcutt CF, Tabashnik BE. Evaluation of pesticide resistance and slope of the concentration-mortality line: are they related? J Econ Entomol 1995; 88:11-20.

13. Daly JC, Fisk JH, Forrester NW. Selective mortality in field trials between strains of Heliothis armigera (Lepidoptera: Noctuidae) resistant and susceptible to pyrethroids: functional dominance of resistance and age class. J Econ Entomol 1988; 81:1000-1007.

14. Denholm I. Insecticide resistance: an avoidable pest management problem. Aspects Appl Biol 1988; 17:239-
246.

15. Dinsdale AB, Cook L, Riginos C, Buckley YM, Barro PD. Refined global analysis of Helicoverpa armigera, mitochondrial cytochrome oxidase I to identify species level genetic boundaries. Ann Entomol Soc Am 2010; 103:196-208.

16. Ferre J, Van RJ. Biochemistry and genetics of insect resistance to Bacillus thuringien sis. Ann Rev Entomol 2002; 47:501-533.

17. Finney DJ. Probit analysis, Edn 3, Cambridge University Press, Cambridge 1971.

18. Forrester NW. Designing, implementation and servicing an insecticide resistance management program. Pest Sci 1990; 28:167-179.

19. Huang S, Han Z. Mechanisms for multiple resistances in field populations of common cutworm, Spodoptera litura (Fabricius) in China. Pestic Biochem Physiol 2007; 87:1422.

20. Ishaaya I, Casida JE. Properties and toxicological significance of esterases hydrolyzing permethrin and cypermethrin in Trichoplusiani larval gut and integument. Pestic Biochem Physiol 1980; 14:178-184.

21. Kontsedalov S, Abu-Moch F, Lebedev G, Czosnek H, Horowitz R, Ghanim M et al. Helicoverpa armigera biotype dynamics and resistance to insecticides in Israel during the years 2008-2010. J Integrative Agric 2012; 11:312-320.

22. Kranthi KR, Jadhav DR, Kranthi S, Wanjari RR, Ali SS, Russell DA et al. Insecticide resistance in five major insect pests of cotton in India. Crop Prot 2002; 21:449460.

23. Kranthi KR, Jadhav DR, Kranthi S, Wanjari RR, Ali SS, Russell DA et al. Carbamate and organophosphate resistance in cotton pests in India, 1995-1999. Bull Entomol Res 2001; 91:37-46.

24. LeOra Software, Polo-PC. A user guide to probit and logit analysis. LeOra Software, Bakeley CA USA, 2003.

25. Litchfield JT, Wilcoxon FA. Simplified method of evaluating dose effect experiments. J Pharmacol Exp Ter 1949; 99:99-103.

26. McCaffery AR, Head DJ, Jianguo T, Dubbeldam AA, Subramaniam VR, Callaghan A et al. Nerve insensitivity resistance to pyrethroids in Heliothine lepidoptera. Pestic Sci 1998; 51: 315-320.

27. Narahashi T. Recent progress in the mechanism of action of insecticides: pyrethroids fipronil and indoxacarb. J Pestic Sci 2001; 26:277-285.

28. Nauen R, Bretschneider T. New modes of action of insecticides. Pesticide Outlook 2002; 13:241-245.

29. Robertson JL, Priesler HK. Pesticide Bioassays with Arthropods. CRC, Boca Raton, FL 1992.

30. Saleem MA, Ahmad M, Ahmad M, Aslam M, Sayyed AH. Resistance to selected organochlorin, organophosphate, carbamate and pyrethroid insecticides in Spodoptera litura (Lepidoptera: Noctuidae) from Pakistan. J Econ Entomol 2008; 101.

31. Salgado VL, Sheets JJ, Watson GB, Schmidt AL. Studies on the mode of action of spinosad: The internal effective concentration and the concentration dependence of neural excitation. Pest Biochem Physiol 1998; 60:103-110.

32. Sayyed AH, Wright DJ. Genetics and evidence for an esterase-associated mechanism of resistance to indoxacarb in a field population of diamondback (Lepidoptera: Plutellidae). Pest Manag Sci 2006; 62:1045-1051. 
33. Sayyed AH, Ahmad M, Saleem MA. Cross-resistance and genetics of resistance to indoxacarb in Spodoptera litura (Lepidoptera: Noctuidae). J Econ Entomol 2008; 101:472479.

34. Sayyed AH, Saeed S, Ann MN, Crickmore N. Genetic biochemical and physiological characterisation of spinosad resistance in Plutella xylostella (Lepidoptera: Plutellidae). J Econ Entomol 2008b; 101.

35. Sayyed AH, Haward R, Herrero S, Ferre J, Wright DJ. Genetic and biochemical approach for characterisation of resistance to Bacillus thuringiensis toxin Cry1Ac in a field population of the diamondback moth. Appl. Environ Microb 2000; 66:1509-1516.

36. Shen JL, Wu YD. Insecticide Resistance in Cotton Bollworm and its Management. China Agricultural Press, Beijing, China, 1995, 259-280.

37. Tabashnik BE, Finson N, Chilcutt CF, Cushing NL, Johnson MW. Increasing efficacy of bioassays: evaluating resistance to Bacillus thuringiensis in diamondback moth (Lepidoptera: Plutellidae). J Econ Entomol 1993; 86:635644.

38. Torres-Vila LM, Molina MCR, Plasencia AL, del Rincon, ABLR. Pyrethroid resistance of Helicoverpa armigera in Spain: current status and agroecological perspective. Agriculture Ecosystems and Environment 2002; 93:55-66.

39. Valles SM, Koehler PG, Brenner RJ. Antagonism of fipronil toxicity by piperonyl butoxide and S, S, S-tributyl phosphorotrithioate in the German cockroach (Dictyoptera: Blattellidae). J Econ Entomol 1997; 90:1254-1258.

40. Yu SJ, Nguyen SN, Abo-Elghar GE. Biochemical characteristics of insecticide resistance in the fall armyworm, Spodoptera frugiperda (J.E. Smith). Pestic Biochem Physiol 2003; 77:1-11.

41. Zhou XM, Huang BO. Insecticide resistance of the common cutworm (Spodoptera litura) and its control strategies. Entomol Knowl 2002; 39:98-102. 